\title{
Focus effects on syllable duration in Cypriot Greek
}

Charalabos Themistocleous

Department of Linguistics, University of Athens, Greece

https://doi.org/10.36505/ExLing-2008/02/0061/000120

\begin{abstract}
The present experimental study examined the effects of focus on the duration of stressed syllable onset and rhyme in words found in prefocal, focal, post focal and neutral position. The main results generated indicate a significant effect of focus position on the segmental duration. Additionally, word final lengthening was demonstrated, whereas no word initial lengthening effects were observed. Furthermore, the results showed rightward lengthening effects and leftward shortening effects due to focus position on stressed syllables.
\end{abstract}

Keywords: duration, stress, focus, prosody.

\section{Introduction}

This experimental study examines the effects of focus position on the duration of stressed syllable onset and rhyme in Cypriot Greek (henceforth $\mathrm{CG}$ ) regarding the following questions: (a) What are the effects of focus position on stress segmental duration? (b) Does focus affects the duration of all syllables within a word in the same way? These questions address critical phonological considerations concerning duration as a means of marking focal domains (c.f. Beckman and Pierrehumbert 1986), as well as considerations about word initial and final lengthening (c.f. Botinis et al. 2001; Turk and Shattuck-Hufnagel 2000).

\section{Methodology}

The target syllable was the stressed ['la] in antepenultimate, penultimate and ultimate position. Three keywords were chosen, with three CV syllables each, with one of them being the target syllable ['la]: ['la.pi.Oos] 'Lapithos', [pi.'la.ðis] 'Pyladis' and [ma.ju.'la] 'Majula'. These were uttered in the carrier-sentence: [i 'elli 'lei_la0os] 'Elli says _ erroneously', in four different focus positions: preceding focus, focus on keyword, following focus and neutral focus. The materials were recorded by six native speakers of CG, in their early twenties. Each speaker had to utter 4 sentences x 3 keywords x 10 repetitions. The total corpus consisted of 720 utterances. The sentences were typed in Greek orthography and each prompt was presented in random order before a subject. The test words were manually segmented and labelled, by using simultaneous inspections of waveforms and wide-band spectrograms following standard criteria (e.g. Peterson and Lehiste 1960). The durations of the syllable [la], the syllable onset [1] and the rhyme [a] were measured.

ExLing 2008: Proceedings of 2nd Tutorial and Research Workshop on Experimental Linguistics, 25-27 August 2008, Athens, Greece 


\section{Results}

Statistical analysis was carried out and the mean durations of syllables in phrases uttered with four distinct foci are shown in Figure 1:

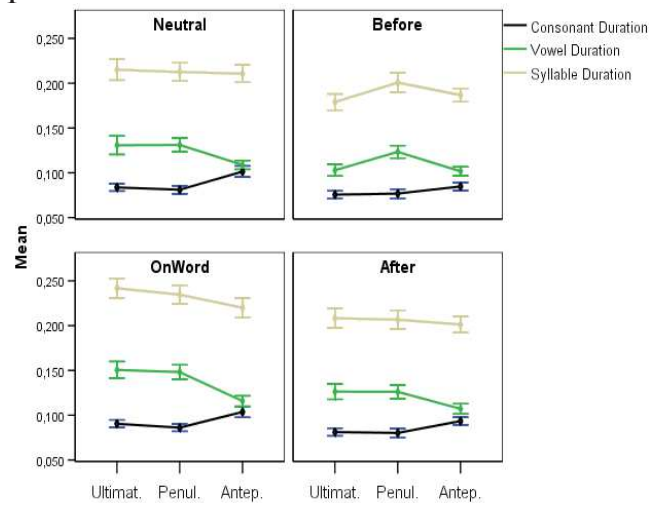

Figure 1. Mean consonant, vowel \& syllable duration in seconds in ultimate, penultimate and antepenultimate position, uttered in words with four distinct focus positions i.e. with neutral focus (Neutral), with focus accent preceding word (Before), with focus on the word (OnWord) and with focus accent following word (After); error bars show Std Dev.

The correlations of FOCUS X SYLLABLE POSITION are shown for consonant, vowel and syllable duration. A two way ANOVA was performed; all effects are reported at a .05 level of significance.

(a) Consonant Duration: Consonants in syllables under focus were longer than in phrases with other focus patterns. Specifically, consonants in antepenultimates under focus $(M=.104)$ were longer than consonants in penultimates $(M=.087)$ and ultimates $(M=.090)$; consonants in syllables with neutral focus followed $(M=.089)$. Interestingly, the shortest consonants were in penultimates with preceding focus $(M=.077)$. Levene's test indicated that the assumption of homogeneity of variance had been violated, $F(11,708)=$ $1.993, p<.05$, however $F$-tests are reported. The results showed that syllable position significantly affected the produced consonant duration, $F(2,708)=46.382, p<.05, r=1$. Focus position affected consonant duration, $F(3,708)=19.478, p<.05, r=1$. Focus position $x$ syllable position interaction was not significant, $F(6,708)=1.383$, ns. Games-Howell post hoc test for syllable position showed significant differences between all groups ( $p<.05$, in all cases), except between ultimates and penultimates, $n s$ and for focus position between all groups ( $p<.05$, in all cases), except between neutral focus and focus following word, and between neutral and focus on word, $n s$.

(b) Vowel Duration: Vowels in syllables under focus were longer than in phrases with other focus patterns (see Figure 1). Specifically, vowels in ultimates under focus $(M=151)$ were longer than vowels in penultimates $(M=.148)$ and antepenultimates and $(M=.116)$. Vowels in syllables with neutral focus follow in mean duration $(M=.124)$. Interestingly, the shortest vowels were in syllables with preceding focus, especially the vowels found in antepenultimates $(M=.102)$ and ultimates $(M=.103)$. Levene's test 
indicated that the assumption of homogeneity of variance had been violated, $F(11,708)=4.204, p<.05$, however $F$-tests are reported. Results showed that syllable position significantly affected vowel duration, $F(2,708)=$ $46.889, p<.05, r=.37$. Focus position significantly affected vowel duration, $F(3,708)=31.392, p<.05, r=.35$. The focus position $x$ syllable position interaction was significant, $F(6,708)=4.159, p<.05, r=.20$. Games-Howell post hoc tests for syllable position revealed significant differences between all groups $(p<.05)$, except between ultimates and penultimates, $n s$. For focus position significant differences were revealed between all groups $(p<.05)$ except between neutral focus and following focus, and between neutral and focus on word $n s$.

(c) Syllable Duration: The duration of syllables in words under focus was longer than in phrases with other focus patterns, especially the duration of ultimates under focus $(M=.242)$ was longer than of penultimates $(M=.235)$ and antepenultimates and $(M=.220)$. Syllables with neutral focus follow in mean duration $(M=.213)$. Interestingly, the shortest syllables were in words with preceding focus, especially antepenultimates $(M=.187)$ and ultimates $(M=.179)$ following the vowels' pattern. The results showed that the main effect of the type of syllable position in the produced duration of syllables significantly affected syllable duration, $F(2,708)=3.338, p<.05, r=.05$. Focus Position significantly affected syllable duration, $F(3,708)=37.542$, $p<.05, r=.36$. Focus position $\mathrm{x}$ syllable position interaction was significant, $F(6,708)=2.314, p<.05, r=.12$. Games-Howell post hoc tests for syllable position within the word revealed significant differences between penultimate and antepenultimate $(p<.05)$; all other cases were nonsignificant $n s$. There were significant effects of focus position in all groups, $(p<.05)$, except between neutral focus and focus following word $n s$.

\section{Discussion}

Results generated support that focus position significantly affects the duration of stressed syllables. Observations on these data, without any accounts of focus position revealed no word final lengthening (see also Turk and Shattuck-Hufnagel 2000; Katsika 2007), attributed to shortening effects of preceding focus accent, most evident on ultimate syllables. As a result penultimates had increased duration comparing to ultimates and antepenultimates. A striking result was the effect of focus position with regards to word final lengthening: When focus was accounted for in the model, stressed ultimate syllables aligning with focus accent showed increased duration comparing to ultimates with preceding focus, which were even shorter than neutral accented syllables. Additionally, stressed antepenultimates and stressed penultimates had a constant relation: syllables with focus $>$ syllables with neutral focus $>$ syllables with following focus $>$ 
syllables with preceding focus accent. Furthermore, stressed syllables had various lengthening due to focus: ultimates were more prone to lengthening or shortening than antepenultimates and penultimates. Although these observations are in accordance with previous studies (c.f. Klatt 1976, Cooper and Paccia-Cooper 1980, Botinis 1989), the small effect size of the tests, along with counter evidence from studies on Athenian Greek (AG) (c.f. Botinis et al. 2001) suggest that these results should be considered with caution. Critical observations were reported for the sub-syllable level (see Turk and Shattuck-Hufnagel 2000): (a) word final lengthening is localized on the 'rime' of the final syllable, the vowel and (b) word initial lengthening is localized on the onset of the initial syllable, the consonant. Even though, the first prediction was confirmed by the data, the second was not; initial word lengthening was not supported by the results of the present study as word initial stressed syllables were found to be shorter in most cases than ultimate and penultimate syllables, despite the fact that the consonants of these syllables were evidently longer. This observation, however, contrasts previous studies on AG (see Botinis et al. 2001, Katsika 2007) that support initial lengthening. However these studies examine AG, while the present one is based on CG data, therefore additional comparative evidence is needed. Furthermore, this study did not take into account the effects of speech tempo. Evidence for the effects of tempo in Greek has been observed by Botinis et al. (2001). Also, comparative measurements from unstressed syllables are essential in assisting the interpretation of these results.

\section{References}

Beckman, M. and Pierrehumbert, J. 1986. Intonational structure in Japanese and English. Phonology Yearbook 3, 255-309.

Botinis, A. 1989. Stress and Prosodic Structure in Greek. Lund: Lund University Press.

Botinis, A., Fourakis, M. and Bannert, R. 2001. Prosodic interactions on segmental durations in Greek. Lund University, Working Papers 49, 10-13.

Cooper, W.E. and Paccia-Cooper, J. 1980. Syntax and speech. Cambridge, MA: Harvard University Press.

Katsika, A. 2007. Duration and pitch anchoring as cues to word boundaries in Greek. Proceedings of the XVIth International Congress of Phonetic Sciences, 929-932. Saarbrücken: Uneversität des Saarlandes.

Klatt, D. 1976. Linguistic uses of segmental duration in English: Acoustic and perceptual evidence. J. Acoust. Soc. Amer. 59(3), 1208-1221.

Peterson, G.E. and Lehiste, I. 1960. Duration of syllable nuclei in English. J. Acoust. Soc. Amer. 32, 693-703.

Turk A.E. and Shattuck-Hufnagel, S. 2000. Word-boundary-related duration patterns in English. Journal of Phonetics 28. 397-440.

Turk, A.E. and White, 1999. Structural influences on accentual lengthening in English. Journal of Phonetics 27, 171-206. 